\title{
The prognostic value of architectural patterns in a study of 37 type $A B$ thymomas
}

I Tudor Vladislav ${ }^{1}$, Yesim Gökmen-Polar ${ }^{1}$, Kenneth A Kesler ${ }^{2}$, Patrick J Loehrer Sr$^{3}$ and Sunil Badve ${ }^{1}$

${ }^{1}$ Department of Pathology and Laboratory Medicine, Indiana University School of Medicine and Indiana University Simon Cancer Center, Indianapolis, IN, USA; ${ }^{2}$ Department of Internal Medicine, Indiana University School of Medicine and Indiana University Simon Cancer Center, Indianapolis, IN, USA and

${ }^{3}$ Department of Surgery, Indiana University School of Medicine and Indiana University Simon Cancer Center, Indianapolis, IN, USA

\begin{abstract}
Spindle cell thymomas with prominent amount of lymphocytes are classified as WHO type AB tumors. However, there are architectural pattern differences in these tumors. We investigated the importance of architectural pattern in type $A B$ thymomas in relation to prognostic value. Archival hematoxylin-eosin stained slides of 37 $A B$ type thymomas were reviewed for the presence (type 1) or absence (type 2) of reticular growth pattern. Reticular growth pattern is defined as the presence of a network of elongated bland spindle cells separating nests of tumor cells admixed with lymphoid cells. The architectural patterns were correlated with tumor stage at diagnosis and presence or absence of recurrent disease. The analysis identified 18 cases of type $1 \mathrm{AB}$ thymoma and 19 cases of type 2. Type 2 cases also had greater cytologic atypia within the spindle cells. Patients with type 1 tumors were more likely to have early stage disease. In contrast, type 2 pattern was associated with higher stage at diagnosis $(P<0.001)$ and greater likelihood for recurrence $(P<0.05)$ and metastases. Architectural features are prognostically relevant in classification of WHO AB type thymomas and may constitute a form of personalized medicine. Independent confirmation of the findings is necessary to confirm the association of architectural
\end{abstract} pattern with outcomes.

Modern Pathology (2014) 27, 863-868; doi:10.1038/modpathol.2013.203; published online 15 November 2013

Keywords: patterns; thymoma; thymus neoplasms; type $A B$

Thymic neoplasms are uncommon tumors arising from thymic epithelial cells. Numerous classification schemes have been proposed over the years. ${ }^{1}$ Owing to difficulties in achieving a consensus regarding thymoma classification, WHO (the World Health Organization) devised a scheme for the histological classification of these tumors. First released in 1999 and then updated in 2004, WHO classification recognizes five main types of thymomas (types A, $\mathrm{AB}, \mathrm{B} 1, \mathrm{~B} 2$, and B3) along with thymic carcinoma. ${ }^{2,3}$ It also recognizes the existence of rare variants such as metaplastic, micronodular sclerosing, microscopic, and anaplastic thymoma.

There is an association of histology with behavior of thymomas. Types A, AB, and B1 were thought of

Correspondence: Dr S Badve, MD, FRCPath, Department of Pathology and Laboratory Medicine, Indiana University School of Medicine and Indiana University Simon Cancer Center, 350 West 11th street, IUHPL 4050, Indianapolis, IN 46202, USA. E-mail: sbadve@iupui.edu

Received 30 July 2013; accepted 21 October 2013; published online 15 November 2013 as benign lesions and in some classification systems combined into one group. However, recent data presented by us and among others have documented recurrences and metastases in both type A and type AB thymomas. ${ }^{4-6}$ More recently, Nonaka and Rosai ${ }^{7}$ have published a series of cases of type A thymomas with distinct atypia (atypical type A thymomas). Some of these cases had aggressive outcomes. We analyzed a series of 23 cases of type A thymomas and found that the presence of necrosis was associated with increased likelihood of recurrence. ${ }^{8}$ These studies suggest that at least in type A thymoma, there is some correlation between histological features and likelihood of recurrence.

At a recent meeting of pathologists in Mannheim (Germany), sponsored by the International Thymic Malignancy Interest Group (ITMIG), the possibility of two existing architectural patterns in type $A B$ thymomas was raised by one of the authors (SB). One pattern being associated with elongated bland fibroblast-like spindle cells and the other characterized by plumper spindle cells. In this study, we classified 37 cases of type $\mathrm{AB}$ thymomas by the two 
architectural patterns and correlated the patterns with clinical data including outcomes.

\section{Materials and methods}

\section{Study Samples}

Indiana University is a referral center for the treatment of patients with thymic malignancies. Patients are most often referred for discussion of chemotherapeutic options. It is our standard practice that all the histology slides are reviewed and whenever possible blocks or unstained slides are obtained and retained for our records. The cases have been collated in a well-annotated database with charts reviewed by a single observer and all slides by a single pathologist (SB). The database contains information with regard to tumor size, presenting symptoms, Masaoka stage at diagnosis, initial treatment, margin status after resection, time elapsed until relapse/recurrence, site of metastases/relapse, and survival. This information was obtained from the patients' charts or from the referral institutions.

After obtaining approval from the Institutional Review Board at Indiana University, the database was queried for spindle cell thymomas of $A B$ type and further reviewed for architectural pattern. The clinical data was correlated with histological findings. We identified 43 cases of spindle cell thymomas with $>10 \%$ lymphocytes; four cases were excluded for lack of detailed clinical information (type AB thymomas; Table 1). All slides were reviewed by two pathologists (ITV and SB).

\section{Histological Criteria}

The hematoxylin and eosin slides of these cases were re-examined for architectural features at $\times 10$ magnification. Two basic forms of architectural patterns were identified (Table 2). Type 1 was characterized by the presence of complete/partial nodules of lymphoid-rich tumor surrounded by

Table 1 Clinical characteristics of the 37 type AB thymomas included in the study

\begin{tabular}{|c|c|c|c|c|c|c|c|c|c|c|c|c|}
\hline & Sex & $\begin{array}{c}\text { Age } \\
\text { (years) }\end{array}$ & $\begin{array}{l}\text { Size } \\
\text { mass } \\
(\mathrm{cm})\end{array}$ & $\begin{array}{l}\text { Stage } \\
\text { at } D X\end{array}$ & $\begin{array}{l}\text { Primary } \\
\text { treatment }\end{array}$ & $\begin{array}{c}\text { Margin status } \\
\text { after } T_{x}\end{array}$ & $\begin{array}{l}\text { Extrathoracic } \\
\text { metastasis }\end{array}$ & $\begin{array}{c}\text { Relapse time } \\
\text { after } \\
D X \text { (months) }\end{array}$ & $\begin{array}{l}\text { Time of } \\
\text { follow-up } \\
\text { (months) }\end{array}$ & $\begin{array}{c}A B \\
\text { subtype }\end{array}$ & Necrosis & $\begin{array}{l}\text { Visceral } \\
\text { lung } \\
\text { invasion }\end{array}$ \\
\hline 1 & M & 68 & 6.8 & I & $\mathrm{S}$ & $<1 \mathrm{~mm}$ & None & No & 29 & 1 & No & No \\
\hline 2 & M & 55 & $\mathrm{~N} / \mathrm{A}$ & I & $\mathrm{S} / \mathrm{C}$ & N/A & N/A & $\mathrm{N} / \mathrm{A}$ & 46 & 1 & No & No \\
\hline 3 & $\mathrm{M}$ & 53 & 6.5 & II & $\mathrm{S}$ & Neg & None & No & 108 & 1 & No & No \\
\hline 4 & $\mathrm{M}$ & 51 & 5.3 & I & $\mathrm{S}$ & $<1 \mathrm{~mm}$ & None & No & 41 & 1 & No & No \\
\hline 5 & $\mathrm{M}$ & 55 & $\mathrm{~N} / \mathrm{A}$ & II & $\mathrm{S}$ & Neg & None & $\mathrm{N} / \mathrm{A}$ & 24 & 1 & No & No \\
\hline 6 & $\mathrm{M}$ & 40 & 4.4 & I & $\mathrm{S}$ & Neg & None & $\mathrm{N} / \mathrm{A}$ & 1 & 1 & No & No \\
\hline 7 & $\mathrm{M}$ & 46 & 5.8 & I & $\mathrm{S}$ & $<2 \mathrm{~mm}$ & None & No & 65 & 1 & No & No \\
\hline 8 & $\mathrm{~F}$ & 72 & 10 & I & $\mathrm{S}$ & Neg & None & No & 149 & 1 & No & No \\
\hline 9 & $\mathrm{~F}$ & 68 & 8.0 & I & $\mathrm{S}$ & $<1 \mathrm{~mm}$ & None & No & 37 & 1 & No & No \\
\hline 10 & $\mathrm{~F}$ & 63 & 6.0 & IIA & $\mathrm{S}$ & Pos & None & No & 20 & 1 & No & No \\
\hline 11 & $\mathrm{~F}$ & 71 & 12 & I & $\mathrm{S}$ & Neg & None & No & 35 & 1 & No & No \\
\hline 12 & $\mathrm{M}$ & 59 & $\mathrm{~N} / \mathrm{A}$ & I & $\mathrm{S}$ & Pos & None & No & 0 & 1 & No & No \\
\hline 13 & M & 41 & 8.5 & II & $\mathrm{S} / \mathrm{R}$ & $<2 \mathrm{~mm}$ & None & No & 117 & 1 & No & No \\
\hline 14 & $\mathrm{M}$ & 63 & $\mathrm{~N} / \mathrm{A}$ & I & $\mathrm{S}$ & Neg & None & $\mathrm{N} / \mathrm{A}$ & 1 & 1 & No & No \\
\hline 15 & $\mathrm{~F}$ & 47 & $\mathrm{~N} / \mathrm{A}$ & II & $\mathrm{S}$ & $<1 \mathrm{~mm}$ & None & No & 104 & 1 & No & No \\
\hline 16 & $\mathrm{~F}$ & 45 & $\mathrm{~N} / \mathrm{A}$ & I & $\mathrm{S}$ & Neg & None & No & 1 & 1 & No & No \\
\hline 17 & $\mathrm{~F}$ & 49 & 4.9 & I & $\mathrm{S}$ & Neg & None & No & 18 & 1 & No & No \\
\hline 18 & $\mathrm{M}$ & 67 & 14 & I & $\mathrm{S}$ & Neg & None & No & 12 & 1 & No & No \\
\hline 19 & $\mathrm{~F}$ & 63 & 5.5 & IVA & $\mathrm{S} / \mathrm{C}$ & Pos & None & No & 68 & 2 & No & No \\
\hline 20 & $\mathrm{M}$ & 77 & $\mathrm{~N} / \mathrm{A}$ & IIA & $\mathrm{S}$ & Neg & None & No & 1 & 2 & No & No \\
\hline 21 & $\mathrm{M}$ & 83 & $5.9 \mathrm{~cm}$ & I & $\mathrm{S} / \mathrm{C} / \mathrm{R}$ & pos & None & No & 11 & 2 & No & No \\
\hline 22 & $\mathrm{~F}$ & 76 & 5.1 & II & $\mathrm{S}$ & $<1 \mathrm{~mm}$ & None & No & 30 & 2 & No & No \\
\hline 23 & $\mathrm{M}$ & 34 & 9.8 & III & $\mathrm{S} / \mathrm{C} / \mathrm{R}$ & Neg & Bone & 47 & 51 & 2 & Yes & Yes \\
\hline 24 & $\mathrm{M}$ & 61 & $\mathrm{~N} / \mathrm{A}$ & IVB & $\mathrm{S}$ & Pos & None & No & 28 & 2 & No & No \\
\hline 25 & $\mathrm{M}$ & 52 & $\mathrm{~N} / \mathrm{A}$ & IVA & $\mathrm{S} / \mathrm{C}$ & Pos & None & 36 & 36 & 2 & No & No \\
\hline 26 & $\mathrm{~F}$ & 35 & 1.7 & I & $\mathrm{S}$ & Neg & None & No & 10 & 2 & No & No \\
\hline 27 & M & 29 & 11.0 & IVA & $\mathrm{S}$ & Pos & None & 241 & 245 & 2 & No & No \\
\hline 28 & $\mathrm{M}$ & 69 & 1.3 & I & $\mathrm{S}$ & Neg & None & No & 75 & 2 & No & No \\
\hline 29 & $\mathrm{M}$ & 48 & 14 & IVA & $\mathrm{S} / \mathrm{C}$ & Pos & None & 67 & 80 & 2 & No & No \\
\hline 30 & $\mathrm{~F}$ & 49 & 8.5 & I & $\mathrm{S}$ & Neg & None & No & 164 & 2 & No & No \\
\hline 31 & $\mathrm{M}$ & 83 & 8.5 & I & $\mathrm{S}$ & Neg & None & No & 38 & 2 & No & No \\
\hline 32 & $\mathrm{M}$ & 42 & $\mathrm{~N} / \mathrm{A}$ & IVA & $\mathrm{S} / \mathrm{R} / \mathrm{C}$ & $\mathrm{N} / \mathrm{A}$ & None & 0 & 42 & 2 & Yes & No \\
\hline 33 & $\mathrm{~F}$ & 66 & 6 & IIA & S & Neg & None & No & 52 & 2 & No & No \\
\hline 34 & $\mathrm{~F}$ & 75 & 4.0 & IIB & $\mathrm{S}$ & $<1 \mathrm{~mm}$ & None & No & 20 & 2 & No & No \\
\hline 35 & $\mathrm{~F}$ & 62 & 2.2 & I & $\mathrm{S}$ & Neg & None & No & 109 & 2 & No & No \\
\hline 36 & $\mathrm{M}$ & 58 & $\mathrm{~N} / \mathrm{A}$ & III & $\mathrm{S} / \mathrm{C} / \mathrm{R}$ & Pos & None & No & 73 & 2 & No & No \\
\hline 37 & $\mathrm{~F}$ & 65 & 4.5 & III & $\mathrm{S}$ & Neg & None & No & 49 & 2 & No & Yes \\
\hline
\end{tabular}

C, chemotherapy; Dx, diagnosis; R, radiotherapy; S, surgery; Tx, treatment. 
Table 2 Histologic features characteristics of types AB 1 and AB 2 thymomas

\begin{tabular}{|c|c|c|}
\hline $\begin{array}{l}\text { Histological } \\
\text { features }\end{array}$ & AB type 1 & AB type 2 \\
\hline Fibrotic bands & No/inconspicuous & Yes/predominant \\
\hline $\begin{array}{l}\text { Reticular growth } \\
\text { pattern }\end{array}$ & Yes/predominant & No/inconspicuous \\
\hline $\begin{array}{l}\text { Type of cells in } \\
\text { intervening } \\
\text { septae }\end{array}$ & Tumor cells & Fibroblasts \\
\hline $\begin{array}{l}\text { Stromal } \\
\text { lymphocytes }\end{array}$ & Sparse & Variable \\
\hline $\begin{array}{l}\text { Character of the } \\
\text { spindle cells }\end{array}$ & Elongated & Plump \\
\hline Nuclear features & Bland & $\begin{array}{l}\text { Irregular with small } \\
\text { nucleoli }\end{array}$ \\
\hline Cytologic atypia & No & Maybe present \\
\hline
\end{tabular}

long, bland spindle cells, which were poor in lymphoid cells. The type 2 tumors were characterized by epithelial islands comprised by spindle/oval cells admixed with variable amounts of lymphocytes or areas of spindle/ovoid cells. The stroma in between the tumor islands of these tumors did not contain slender tumor cells. In all cases, cytological features were also evaluated at $\times 40$ magnification to identify atypical cells. These were defined as cells that were large, plump spindle cells with either vacuolated chromatin or hyperchromatic nuclei that often contained pink nucleoli. Mitotic activity in these tumors was sparse to absent.

\section{Statistical Analysis}

Patients were dichotomized into two groups based on architectural patterns for the purposes of the analysis. The primary endpoint for the analysis was recurrence/metastases. The statistical plan included performance of the Mann-Whitney test, Fisher exact test and the $\chi^{2}$ test for analysis of continuous and categorical variables, respectively. All tests were two-sided, and a $P$-value of 0.05 was considered to be significant. Statistical analysis was performed using GraphPad software (La Jolla, CA, USA).

\section{Results}

\section{Architectural Pattern of Tumors}

Eighteen of the 37 cases were classified as type 1 using characteristics described in Table 2. All of the cases had characteristic features of islands of lymphocyte-rich tumor separated by bland spindle cells (Figure 1a) giving rise to reticular pattern (Figure 1b). The tumor cells forming the reticulum were elongated spindle cells that lacked cytologic atypia or mitotic activity (Figure 1c). The tumor islands were composed of spindle cells admixed with variable amounts of lymphocytes (Figure 1d). The nuclei of these cells were oval with finely divided chromatin. Nucleoli were either absent or indistinct and lacked mitotic activity. There was no evidence of necrosis or vascular invasion in these tumors. Invasion of surrounding structures was also not apparent in the sections examined.

The remaining 19 cases were classified as type 2 . These consisted of sheets of tumor cells admixed with lymphocytes separated by bands of fibrotic stroma (Figures 2a and b). The tumor cells tended to be plump spindle to oval cells with open vesicular nuclei. The nuclear chromatin was often granular with readily identifiable nucleoli, which were prominent in nine cases (Figure 2c). In rare cases, mitotic activity was noted in these cells, particularly at the junction with the supporting stroma. The stroma was often acellular and composed of dense fibrous tissue without tumor cells but may have contained a few lymphocytes (Figure 2d). Microscopic foci of necrosis were noted in two cases. Invasion of the adjacent lung parenchyma was also noted in two cases.

\section{Patient Characteristics}

The study included 37 adult patients with an age distribution of 32-83 years. The tumors ranged in size from 1.7 to $14 \mathrm{~cm}$. The predominant stage at diagnosis was stage I (Table 3) but nine patients had locally advanced disease at presentation. Twentyeight patients were treated with surgery alone, whereas nine patients had additional adjuvant chemoradiation therapy. Four patients had relapse and one developed metastases.

Type 1 tumors. The average age of patients with type 1 tumors was 56 years (range, 40-68 years), with M:F ratio of 1.6:1 (Table 3). The stage at the time of diagnosis of these tumors was either stage I (13 cases) or stage II (5 cases). Tumors weighed from 95.6 to $810 \mathrm{~g}$ and ranged in size from 4.4 to $14 \mathrm{~cm}$ in the greatest dimension. At the time of surgery, all type 1 tumors showed multinodular growth pattern. In five cases, tumor was documented as encapsulated. In the remaining cases, data regarding encapsulation was not available.

Treatment. In 16 cases, the patients were treated with surgery alone. Postsurgical margins were reported to be positive in two cases. In two patients, adjuvant chemo/radiotherapy was instituted. None of these patients developed relapse during the follow-up time, which ranged from 0 to 149 months (average, 47 months).

Type 2 tumors. The average age for type 2 pattern was 59 years (range, 29-83 years) and the M:F ratio was 1.4:1. The stage at diagnosis for these 19 tumors was stage I in six cases, stage II in four cases, stage III in three cases, and stage IV in six cases. Tumors 

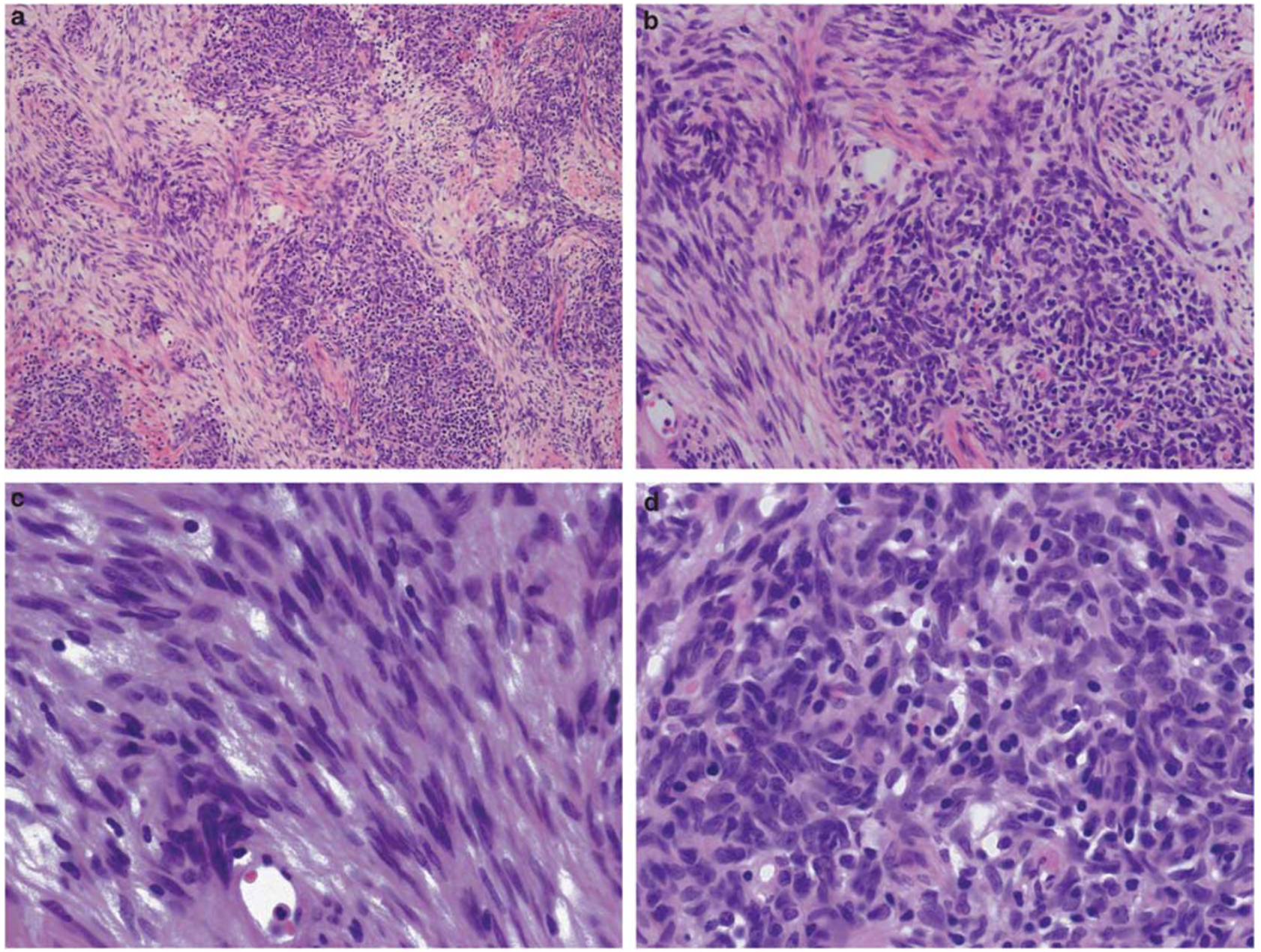

Figure 1 WHO AB thymoma type 1. (a) The microphotograph shows a reticular architecture (low magnification; $\times 4$ ). (b) The reticular architecture is due to small tumor nests surrounded by elongated bland appearing spindle cells $(\times 10$ magnification). (c) The elongated spindle cells have indistinct nucleoli and lack mitotic activity (high magnification; $\times 40$ ). (d) Tumor nests composed of spindle cells admixed with lymphocytes (high magnification; $\times 40$ ).

weighed from 51 to $519 \mathrm{~g}$ and ranged in size from 1.7 to $14 \mathrm{~cm}$ in greatest dimension. At the time of surgery, three tumors were documented as a single nodule. The remaining cases showed multinodular growth pattern. In six cases, tumor was documented as encapsulated.

Treatment. Twelve patients were treated with surgery alone and seven cases with a combination of surgery and chemo/radiotherapy. Six patients had positive margins after surgical resection. Four patients of these 19 patients (20\%) developed relapse/metastases at the average follow-up of 65.6 months (range, 0-245 months). The relapses involved the lungs at 36, 47, 67, and 241 months, respectively, after the initial diagnosis. In addition, one patient (5\%) developed extrathoracic metastasis involving a long bone.

\section{Statistical Analysis}

As detailed above, there were no major differences in the age, gender, and tumor size so the statistical analysis was restricted to stage at diagnosis and relapse of disease. None of the 18 patients who had type 1 architecture had stage III or IV disease at diagnosis. In contrast, nine of the 19 patients with type 2 architecture had stage III or IV disease at diagnosis $(P=0.0011)$. More importantly, although patients with type $2 \mathrm{AB}$ thymomas had received more aggressive treatment, they were more likely to develop recurrences $(P=0.047)$. Multivariable analysis was not possible and it could be determined whether architectural pattern is an independent prognostic feature.

\section{Discussion}

The classification of thymomas broadly divides tumors into two categories based on the morphological characteristics. The tumors are thus classified as being either composed of spindle cells (type A) or composed of epithelioid/polygonal cells (type B). Further classification of the tumors is, however, 

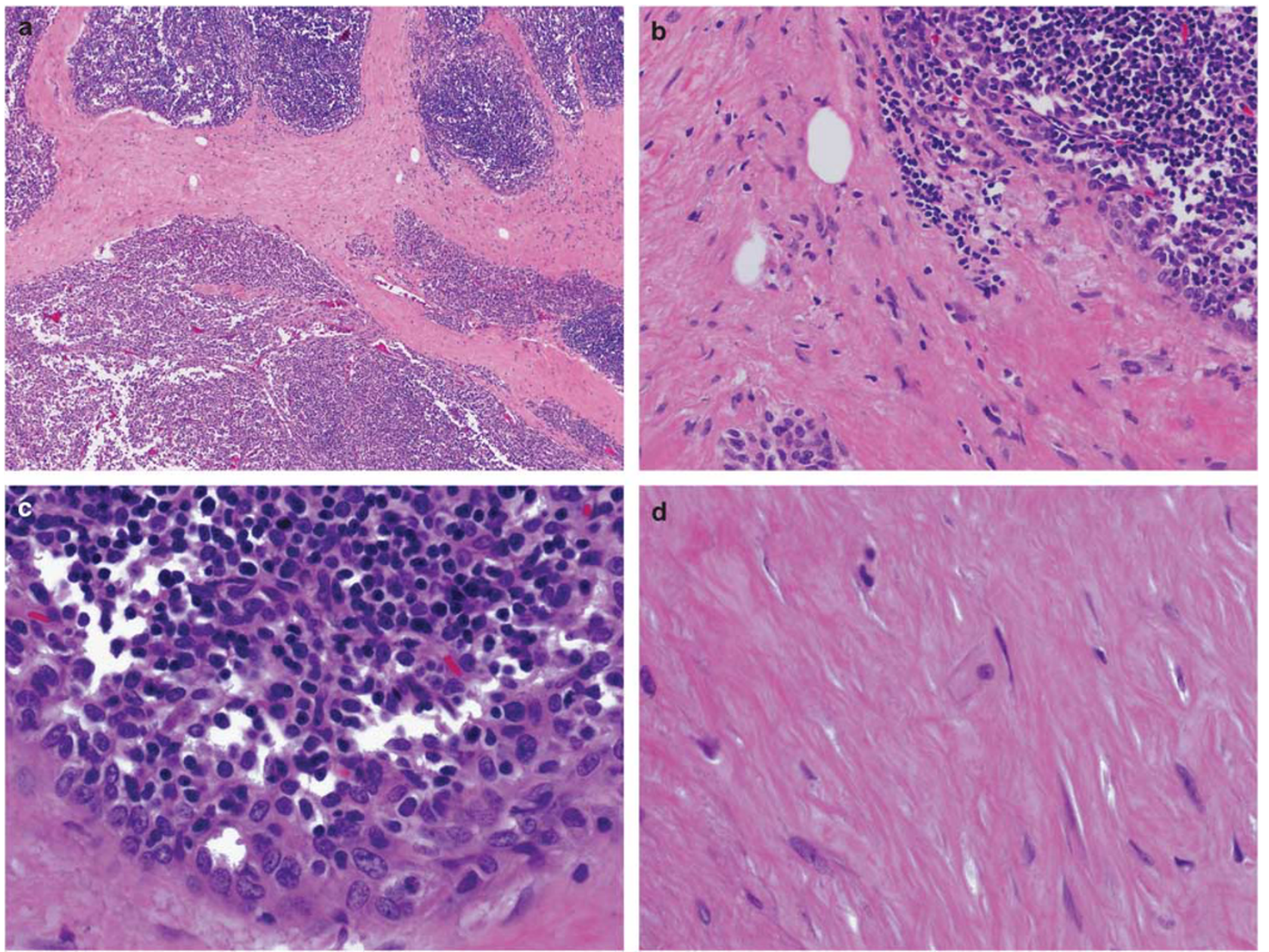

Figure 2 WHO AB thymoma type 2. (a) The microphotograph shows bands of fibrosis dividing tumors into irregular islands (low magnification; $\times 4$ ). (b) The tumor is composed of admixture of plump spindle cells and lymphocytes; the amounts of lymphocytes can be variable (low magnification; $\times 10$ ). (c) The tumor islands are composed of plump spindle cells admixed with lymphocytes. The cells may show variable degree of cytological atypia (high magnification; $\times 40$ ). (d) The stroma is composed of fibroblastic cells and does not contain tumor cells but may contain a few lymphocytes (high magnification; $\times 40$ ).

Table 3 Summarized correlation between histological data and clinical outcome

\begin{tabular}{lccc}
\hline & $\begin{array}{c}\text { Type 1 } \\
(\mathrm{n}=18)\end{array}$ & $\begin{array}{c}\text { Type 2 } \\
(\mathrm{n}=19)\end{array}$ & P value \\
\hline $\begin{array}{l}\text { Average age (range) } \\
\text { Stage I-II }\end{array}$ & $18(40-68)$ & $59(29-83)$ & Not significant \\
Stage III-IV & - & 10 & 0.0011 \\
Maximum tumor size & $14 \mathrm{~cm}$ & 9 & \\
Surgery alone & $16(89 \%)$ & $12(63 \%)$ & Not significant \\
Adjuvant therapy & $2(11 \%)$ & $7(37 \%)$ & Not significant \\
Relapse & 0 & $4(21 \%)$ & 0.047 \\
Metastasis & 0 & $1(5 \%)$ & Not significant \\
\hline
\end{tabular}

based on the character of the tumor microenvironment rather than on the character of the tumor cells. Depending on the number of lymphocytes, tumors are subclassified as B1, B2, or B3. Similarly, type A tumors with significant lymphoid infiltration are subclassified as AB. Of note, tumor architecture is not considered as a parameter for the classification.

During the course of routine diagnostic work, one of the authors (SB) recognized two distinct growth patterns in type $A B$ tumors. The possibility of two subtypes of tumors based on this characteristic was further supported at the Mannheim meeting by many experts including Professor Juan Rosai. The current study was designed to address the issues regarding the prognostic significance, if any, of these two subtypes.

Thirty-seven cases of type $\mathrm{AB}$ thymoma were identified in our data set. One limitation of the dataset was that the cases were often referred for possible chemotherapy; this may lead to overrepresentation of more aggressive cases. In addition, sampling of the cases at referring institutions and the number of slides available for review were uncontrolled variables. Excellent studies by Suster 
and Moran have documented the importance of sampling in subtyping thymic tumors. ${ }^{9,10}$ In spite of these limitations, there was a clear association between tumor architecture and likelihood of response. More specifically, none of the cases with nodular growth pattern and bland spindle cells (type 1) showed recurrence.

Cases that did not show the reticular growth pattern with spindle cells separating the nodules were also more likely to show cytological atypia. The admixture of lymphocytes makes cellular atypia difficult to evaluate in type $\mathrm{AB}$ tumors. This evaluation was easier in zones immediately adjacent to the fibrous stroma (Figure 2c). Nine of these 19 cases contained tumor cells that had vesicular nuclei with distinctly visible nucleoli. These cases were also more likely to exhibit mitotic activity in the plump spindle cells. All nine cases presented with a high tumor stage (III or IV) at diagnosis $(P<0.001)$. In addition, four of these cases were associated with recurrences $(P<0.05)$ and one with metastases. Atypia in type A tumors has been recently described by Nonaka and Rosai; ${ }^{7}$ it is thought to be associated with aggressive clinical features. In our prior study of type A tumors, tumor necrosis, but not cellular atypia, was associated with recurrences. ${ }^{8}$

The absence of recurrences or metastases in patients with type 1 pattern is worth noting. It is possible that patients with these histological features might be spared of adjuvant therapies. It is well recognized that a vast number of patients offered chemotherapy derive little or no benefit from these therapies. This has led to the emphasis on personalized medicine and development of algorithms (or molecular signatures) to identify patients least likely to recur and or develop metastases. It is now well-documented that thymomas of all types can recur. The availability of a simple histological feature to identify patients who are not likely to develop adverse outcomes would be a significant advance. Confirmation of the findings of this study in additional cohorts might prove this to be the case.

Architectural differences in type AB thymoma are associated with clinical outcomes. The presence of nodular growth pattern with intervening bland spindle cells (type 1) was associated with early stage $(P<0.001)$ and lesser likelihood of recurrence $(P<0.05)$. This is the first study linking two distinct morphological differences with clinical outcomes such as stage, recurrence, and metastases. Further confirmation of the data is necessary to identify whether architectural pattern is an independent prognostic feature.

\section{Acknowledgments}

This work was supported by the Department of Pathology, Indiana University and Indiana University Simon Cancer Center.

\section{Disclosure/conflict of interest}

The authors declare no conflict of interest.

\section{References}

1 Müller-Hermelink HK, Marx A. Pathological aspects of malignant and benign thymic disorders. Ann Med 1999;31(Suppl 2):5-14.

2 Rosai J, Sobin LH. Thymoma, In: Rosai J, Sobin LH(eds) World Health Organization, International Histological Classification of Tumours: Histological Typing of Tumours of the Thymus, 2nd edn. Springer: Berlin, 1999, pp 9-14.

3 Marx A, Ströbel P, Zettl A, et al. Thymomas, In: Travis WD, Brambilla E, Muller-Hermelink HK, Harris CC (eds). World Health Organization Classification of Tumours: Pathology and Genetics of the Lung, Pleura, Thymus and Heart. IARC Press: Lyon, France, 2004, pp 153-171.

4 Jain RK, Mehta RJ, Henley JD, et al. WHO types A and AB thymomas: not always benign. Mod Pathol 2010;23:1641-1649.

5 Moran CA, Kalhor N, Suster S. Invasive spindle cell thymomas (WHO Type A): a clinicopathologic correlation of 41 cases. Am J Clin Pathol 2010;134:793-798.

6 Vladislav T, Jain RK, Alvarez R, et al. Extrathoracic metastases of thymic origin: a review of 35 cases. Mod Pathol 2012;25:370-377.

7 Nonaka D, Rosai J. Is there a spectrum of cytologic atypia in type a thymomas analogous to that seen in type B thymomas? A pilot study of 13 cases. Am J Surg Pathol 2012;36:889-894.

8 Vladislav IT, Gokmen-Polar Y, Kesler KA, et al. The role of histology in predicting recurrence of type $A$ thymomas: a clinicopathologic correlation of 23 cases. Mod Pathol 2013;26:1059-1064.

9 Moran CA, Suster S. The World Health Organization (WHO) histologic classification of thymomas: a reanalysis. Curr Treat Opt Oncol 2008;9:288-299.

10 Suster S, Moran CA. Thymoma classification: current status and future trends. Am J Clin Pathol 2006; 125:542-554. 